Research Article

\title{
Spectrum of congenital malformations in newborns: in a medical college hospital in South India
}

\author{
Basavanthappa SP, Rajath Pejaver*, Srinivasa V, Raghavendra K, Suresh Babu MT
}

Department of Pediatrics, Basaveshwara Medical College Hospital and Research Centre, Chitradurga, Karnataka, India

Received: 6 July 2014

Accepted: 19 July 2014

\section{*Correspondence:}

Dr. Rajath Pejaver,

E-mail: rajath.pejaver@gmail.com

Copyright: ( ) the author(s), publisher and licensee Medip Academy. This is an open-access article distributed under the terms of the Creative Commons Attribution Non-Commercial License, which permits unrestricted non-commercial use, distribution, and reproduction in any medium, provided the original work is properly cited.

\section{ABSTRACT}

Background: The study was carried out with the aim to determine the overall rate of congenital malformations, incidence in live births and stillbirths, as well as incidence affecting various organ systems, at a medical college hospital in Karnataka and compare them to previous studies

Methods: All intramural deliveries between June 2012 and March 2014 were included in the study. All the new-borns were examined for congenital malformations soon after birth and every day during routine ward rounds. Relevant radiological, histo-hematological and genetic tests were carried out.

Results: During the study period there were 3016 births out of which 2941 were live births and 75 were still born. 93 babies had one or more malformations. The overall incidence of malformations was $3.083 \%$. Incidence of malformations among live births was $2.72 \%$ whereas it was $17.33 \%$ among still born babies. Musculoskeletal malformations accounted for $27.5 \%$ of all the malformations. This was followed by cutaneous $19.16 \%$, genitourinary $15.83 \%$, gastrointestinal $12.5 \%$, neurological $10 \%$ and cardiac $5.83 \%$.

Conclusion: Congenital anomalies are a major cause of stillbirths and infant mortality. Musculoskeletal malformations were the commonest system involved. Still born babies had a significantly higher incidence of malformations and also had a higher incidence of multiple malformations.

Keywords: Congenital malformations, New-born, Still born

\section{INTRODUCTION}

A congenital anomaly may be narrowly defined in terms of physical structure as a malformation, an abnormality of physical structure or form usually found at birth or during the first few weeks of life; ${ }^{1}$ or defined more widely to include functional disturbance as a defect, any irreversible condition existing in a child before birth in which there is sufficient deviation in the usual number, size, shape, location or inherent character of any part, organ, cell or cell constituent to warrant its designation as abnormal. ${ }^{2}$ A congenital anomaly is thus any alteration present at birth of normal anatomic structure and has cosmetic, medical or surgical significance.
According to WHO, the term "congenital malformations" should be confined to structural defects present at birth. ${ }^{4}$ Congenital malformations account for $8-10 \%$ of all perinatal deaths and $13-16 \%$ of all Neonatal deaths. ${ }^{3}$ With improvement in perinatal and neonatal care, birth defects will become leading cause of neonatal mortality and morbidity. ${ }^{2}$ As other causes of infant mortality like infections and nutritional deficiencies are being brought under control, congenital malformations are rapidly emerging as one of the major worldwide problem. ${ }^{5,6}$ For more than two decades, congenital anomalies have been the leading cause of infant mortality in the United States. ${ }^{9}$ In spite of the frequency of congenital anomalies the underlying causes for most remain obscure. Around $40 \%$ $60 \%$ of congenital anomalies are of unknown etiology. ${ }^{9,10}$ 
The prevalence rate of congenital anomalies is increasing due to exposure of teratogens of various kinds. ${ }^{11}$ In India congenital malformations have emerged as the third commonest cause of perinatal mortality.

The present study was carried out with the aim to determine the overall rate of congenital malformations, incidence in live births and stillbirths, as well as incidence affecting various organ systems, at a medical college hospital in Karnataka and compare them to previous studies.

\section{METHODS}

This study was conducted in department of pediatrics at Basaveshwara Medical College Hospital, Chitradurga, Karnataka. All the intramural deliveries between June 2012 to March 2014 comprised the study material. There were a total of 2941 live births and 75 stillbirths during this period. All the newborns were examined for congenital malformations soon after birth and every day during routine ward rounds. Relevant information regarding maternal age, gestational age, sex, community, birth weight, birth order and consanguinity was documented. Significant antenatal history like maternal illness, ingestion of drugs, exposure to radiation and complications of labor was recorded. Antenatal ultrasonography (USG) findings were noted. Relevant radiological, histo-hematological and genetic tests were carried out. Autopsy was done on stillbirth and neonatal death, whenever parents consent could be obtained. Karyotyping was done. A meticulous general and systemic examination was carried out by a consultant at the time of birth to detect any malformations. Ultrasound was employed routinely to detect multiple congenital anomalies and to rule out majority of the internal congenital anomalies. 2D echocardiography was also used for all congenital heart diseases, along with the routine X-ray chest and electrocardiogram. Computed Tomography (CT) scan were advised only for certain special cases. Malformations were divided into major and minor; major malformation interferes considerably with the function of all or part of the infant, minor malformation gives no serious medical or cosmetic consequences to the patients. The major malformations were divided into Central Nervous System (CNS), musculoskeletal, gastrointestinal, genitourinary, CardioVascular System (CVS), syndromes and miscellaneous disorders. Statistical analysis was done using $\mathrm{Z}$ test and Chi-square test.

\section{RESULTS}

During the study period there were 3016 births out of which 2941 were live births and 75 were still born. 93 babies had one or more malformations. The overall incidence of malformations was $3.083 \%$. Incidence of malformations among live births was $2.72 \%$ whereas it was $17.33 \%$ among still born babies. Still born babies had a significantly higher incidence of malformations and also had a higher incidence of multiple malformations (Table 1).

Table 1: Profile of study population.

\begin{tabular}{|lll|}
\hline Details & Numbers & Percentage \\
\hline \multicolumn{2}{|l|}{ Total births } & 3016 \\
\hline - $\quad$ Live births & 2941 & 97.51 \\
\hline - $\quad$ Still births & 75 & 2.4 \\
\hline $\begin{array}{l}\text { Neonates with } \\
\text { malformations }\end{array}$ & 93 & 3.083 \\
\hline - $\quad$ Live births & 80 & 2.72 \\
\hline - $\quad$ Still births & 13 & 17.33 \\
\hline Total malformations & 120 & 3.97 \\
\hline - $\quad$ Live births & 106 & 3.60 \\
\hline - $\quad$ Still births & 14 & 18.66 \\
\hline
\end{tabular}

Musculoskeletal malformations were the commonest malformation and accounted for $27.5 \%$ of all the malformations. This was followed by cutaneous $19.16 \%$, genitourinary $15.83 \%$, gastrointestinal $12.5 \%$, neurological $10 \%$ and cardiac $5.83 \%$ (Table 2).

Table 2: Distribution of congenital malformations.

\begin{tabular}{|lll|}
\hline System & Number & Percentage \\
\hline Musculoskeletal & 33 & 27.5 \\
\hline Cutaneous & 23 & 19.16 \\
\hline Genitourinary & 19 & 15.83 \\
\hline Gastrointestinal & 15 & 12.5 \\
\hline Neurological & 12 & 10 \\
\hline Cardiac & 7 & 5.83 \\
\hline Spine & 4 & 3.33 \\
\hline Eyes & 2 & 1.66 \\
\hline Others & 5 & 4.16 \\
\hline
\end{tabular}

Musculoskeletal and cutaneous malformations were more common among live births, whereas central nervous system malformations were more common among still births.

\section{DISCUSSION}

The incidence of congenital malformations in this study is $3.083 \%$. Singh et al. from India who reported a frequency of $1.5 \%$ and Golalipour et al. from Iran $(1.01 \%) .{ }^{15,16}$ Desai et al. from Bombay, India, Fatema et al from Bangladesh found a little higher incidence of $3.61 \%$ and $3.68 \%$ respectively. ${ }^{17,18}$

The slightly higher incidence of congenital malformations in our study can be attributed to the low socioeconomic status of the majority of the patients, poor antenatal care. Many of the patients had not undergone antenatal ultrasonography. Other factors include differences in study protocol, geographical and race. Frequency of congenital malformation was slightly higher in males in our series. Congenital anomalies were 
seen more in young and older mothers. Similar findings were observed by others.

One study from India and another from Iran found musculoskeletal anomalies as highest in order $(30.60 \%$ and $30.10 \%$ respectively). ${ }^{15,16}$

Fatema et al. from Bangladesh and Tomatir et al. from Turkey found that central nervous system abnormality were the highest in position in their studies $(46.67 \%, 31 \%$ respectively). ${ }^{18,22}$

The low prevalence of cardiovascular defects at birth is due to the fact that most CHD's become symptomatic by 2-4 months of age. Among congenital heart anomalies VSD was the most common. In chromosomal anomalies Down's syndrome was most frequently seen. Congenital talipes equino varus was the commonest musculocutaneous abnormality observed in our study. Among the genitourinary tract anomalies, hypospadias, undescended testis, and polycystic kidney were the most prevalent lesions.

Consanguinity of marriage, maternal exposure to some drugs, maternal disease, maternal smoking habit have some relation with congenital malformations.

\section{CONCLUSION}

Congenital anomalies are a major cause of stillbirths and infant mortality. By thorough clinical examination, the life-threatening congenital malformation must be identified, as early diagnosis and surgical correction of the malformed babies offer the best chance for survival. Stringent antenatal ultrasonography may be able to pick up major, life threatening congenital anomalies.

Funding: No funding sources

Conflict of interest: None declared

Ethical approval: The study was approved by the institutional ethics committee

\section{REFERENCES}

1. Sadler TW. Congenital malformations. In: Sadler TW, eds. Langman's Medical Embryology. 8th ed. Philadelphia: Lippincott Williams \& Wilkins; 2000: 95.

2. Hudgins L, Cassidy SB. Congenital anomalies. In: Martin RJ, Fanroff AA, Walsh MC, eds. NeonatalPerinatal Medicine. 8th ed. Philadelphia: MosbyElsivier; 2006: 561-581.

3. Grover N. Congenital malformations in Shimla. Indian J Pediatr. 2000:67;249-51.

4. Park K. Congenital malformations. In Park K, eds. Park's Textbook of Preventive and Social Medicine. 15th ed. Jabalpur, India: M/S Banarsidas Bhanot; 2005: 379-380.

5. CDC and EUROCAT. Monitoring birth defect, 2012. Available at: http://www.cdc.gov/ncbddd/bd/- monitoring. htm EUROCAT, European Network of Congenital Anomaly Registers.

6. Kumar MR, Bhat BV, Oumachigui A. Perinatal mortality trends in a referral hospital. Indian $\mathbf{J}$ Pediatr. 1996;63:357-61.

7. Chaturvedi P, Banerjee KS. Spectrum of congenital malformations in the new-borns from rural Maharashtra. Indian J Pediatr. 1989;56:501-7.

8. Petrini J, Damus K, Russell R, Poschman K, Davidoff MJ, Mattison D. Contribution of birth defects to infant mortality in the United States. Teratology. 2002;66(Suppl 1):3-6.

9. Kalter H, Warkany J. Medical progress. Congenital malformations: etiologic factors and their role in prevention. N Engl J Med. 1983;308:424-33.

10. Nelson K, Holmes LB. Malformations due to presumed spontaneous mutations in new-born infants. N Engl J Med. 1989;320:19-23.

11. Jensen TK. Children's health and environmental: a review of evidence. In: Jensen TK, eds. A Joint Report from the European Environment Agency and the WHO Regional Office for Europe. Europe: Official Publications of the European Communities; 2002: 116-26.

12. Gustavson $\mathrm{K}$, Jorulf $\mathrm{H}$. Recurrence risks in a consecutive series of congenitally malformed children dying in the perinatal period. Clin Genet. 1976;9:307-14.

13. Khoshnood B, De Vigan C, Vodovar V, Goujard J, Lhomme A, Bonnet D, et al. Trends in prenatal diagnosis, pregnancy termination, and perinatal mortality of newborns with congenital heart disease in France, 1983-2000: a population-based evaluation. Pediatrics. 2005;115(1):95-101.

14. Stoll BJ. Congenital anomalies. In: Kliegman RM, Jenson HB, Behrman RE, Stanton BF, eds. Nelson Textbook of Pediatrics. 18th ed. Philadelphia: WB Saunders; 2008: 711-713.

15. Singh A, Gupta RK. Pattern of congenital anomalies in new-borns: a hospital based prospective study. J K Sci. 2009;1:34-6.

16. Golalipour MJ, Ahmadpour-Kacho M, Vakili MA. Congenital malformations at a referral hospital in Gorgan, Islamic Republic of Iran. East Mediterr Health J. 2005;11:707-15.

17. Desai NA. Congenital anomalies: a prospective study at a teaching hospital. Indian $\mathbf{J}$ Pediatr. 1999;94:413-9.

18. Fatema K, Begum F, Akter N, Zaman SM. Major congenital malformations among the newborns in BSMMU hospital. Bangladesh Med J. 2011;40:712.

19. Datta V, Chaturvedi P. Congenital malformations in rural Maharastra. Indian Pediatr. 2000;37:988-1001.

20. Asindi, Hifzi IA. Major congenital malformations among Saudi infants admitted to Asir central hospital. Ann Saudi Med. 1997;17:250-3.

21. Ekewre OE, McNeil R, Agim B, Jeminiwa B, Oni $\mathrm{O}$, Pam S. A retrospective study of congenital 
anomalies presented at tertiary health facilities in Jos, Nigeria. JPCS. 2011;3:24-8.

22. Tomatir AG, Demiran H, Sorkun HC, Koksal A, Ozerdem F, Glengir N. Major congenital anomalies: a five year retrospective regional study in Turkey. $\mathrm{J}$ Genet Mol Res. 2009;8:19-27.
23. Anand JS, Javadekar BB, Belani M. Congenital malformations in 2000 consecutive births. Indian Pediatr. 1988;25:845-51.

DOI: 10.5455/2349-3933.ijam20140807

Cite this article as: Basavanthappa SP, Pejaver R, Srinivasa V, Raghavendra K, Suresh Babu MT.

Spectrum of congenital malformations in newborns: in a medical college hospital in South India. Int J Adv

Med 2014;1:82-5. 